\title{
2 Role of halogen substituents in a series of polymorphic 3 2,5-diamino-3,6-dicyanopyrazine derivatives with highly flexible groups
}

\author{
Yoko Akune ${ }^{\mathrm{I}}$, Risa Hirosawa ${ }^{\mathrm{I}}$, Atsushi Koseki ${ }^{\mathrm{I}}$, Shinya Matsumoto ${ }^{*}, \mathrm{I}$ \\ I Department of Environment and Natural Sciences, Graduate School of Environment and Information Sciences, Yokohama National \\ University, 79-7, Tokiwadai, Hodogaya-ku, Yokohama 240-8501, Japan
}

Received; accepted

\section{Conformational polymorphism / halogen interaction / substituent effect / conformational potential surface / 2,5-diamino-3,6-dicyanopyrazine}

\begin{abstract}
The crystal structures of the ortho-X-benzyl derivatives, where $\mathrm{X}=\mathrm{F}, \mathrm{Cl}, \mathrm{Br}, \mathrm{I}$, and $\mathrm{Me}$, of 2,5-bis( $N, N$-dibenzylamino)-3,6-dicyanopyrazine dyes $\left(\mathrm{C}_{34} \mathrm{H}_{24} \mathrm{~N}_{6} \mathrm{X}_{4}\right)$ were analysed to evaluate the effect of a series of halogen species on the occurrence of polymorphs. Detailed crystal structure analysis indicated that the thermally stable forms of the polymorphic derivatives $(\mathrm{Cl}$ and $\mathrm{Br}$ derivatives) were closed-packing, whereas those of the non-polymorphic derivatives ( $\mathrm{F}$ and I derivatives) were stabilised by an intermolecular interaction involving theortho-substituents. In the thermally metastable forms of the polymorphic derivative, halogen-halogen and halogen-nitrogen interactions contributed to the stabilisation of these crystal structures in the same way as the thermally stable form of the non-polymorphic derivatives. This indicated that the ease of polymorph occurrence would require an appropriate balance between the crystal energy of the closed-packing structure and that of the crystal structure generated mainly by the electrostatic interactions involving the halogens in these halogenated pyrazine derivatives. In addition, the similar tendency of the occurrence of polymorphs in these halogenated pyrazine derivatives was found in 19 sets of halogenated compounds having known crystal structures of $\mathrm{F}, \mathrm{Cl}, \mathrm{Br}$ and I derivatives including at least one polymorphic derivative in the crystal structure database.
\end{abstract}

\section{Introduction}

Polymorphism is a phenomenon according to which a compound has two or more crystal structures. ${ }^{[1-2]}$ In conformational polymorphism, ${ }^{[3-6]}$ the molecular conformations among polymorphs are different. The differences in conformation and packing arrangement have

Author

Yoko AkuneI, Risa HirosawaI, Atsushi KosekiI, Shinya Matsumoto*,I
Title

Role of halogen substituents in a series of polymorphic 2,5-diamino-3,6-dicyanopyrazine derivatives with highly flexible groups $\begin{array}{lll}\text { File Name } & \text { Date } & \text { Page } \\ \text { revised_ortho_Z } & 07.09 .2018 & 1(18)\end{array}$

Krist_1 
an impact on the physicochemical properties of the polymorphs such as solubility, melting point, and colour. These solid state properties play an important role in industrial products ${ }^{[7-14]}$ and the change in these properties via phase transitions between polymorphs are relevant to functional materials such as chemical sensors because their phase transition is frequently induced by external stimuli. ${ }^{[15-21]}$ As such, understanding the chemical structures that favour polymorphs is important for the design of novel functional materials as well as for polymorph prediction. Hydrogen bond is well-known as a typical structural factor favouring polymorphs. ${ }^{[4]}$ The various motifs of hydrogen bond have contributed to the formation of different crystal packings in many previously reported polymorphic compounds. ${ }^{[22-26]}$ Similarly, halogen interactions have a variety of interaction motifs such as $\mathrm{X} \cdots \mathrm{X}$ interactions, $\mathrm{X} \cdots$ heteroatom interactions, and $\mathrm{C}-\mathrm{H} \cdots \mathrm{X}$ interactions, where $X$ represents halogen atoms. ${ }^{[27-34]}$ The variety of the interaction motifs is also correlated to the occurrence of polymorphs in halogenated compounds. ${ }^{[35]}$ However, the effect of halogen atom type on the occurrence of polymorphs has not been sufficiently studied as relatively few compounds, which have a series of halogenated derivatives (fluoro-, chloro-, bromo-, and iodo-derivatives) have been reported. The strength and direction of these halogen interactions are dependent on the type of halogen atom and thus, identifying a suitable halogen atom during the process of molecular design could induce the occurrence of polymorphs in a compound.

The 2,5-diamino-3,6-dicyanopyrazine dye $\mathbf{1}$ (shown in Scheme 1) is a known fluorophore. Its derivatives exhibit intense fluorescence in both solution and solid states. ${ }^{[36-38]}$ We found that a series of benzyl derivatives $\mathbf{4}, \mathbf{5}, \mathbf{7}$, and $\mathbf{8}$ exhibit conformational polymorphism with different colours (such as yellow, orange, and red) because of their conformational differences. ${ }^{[39]}$ Moreover, we have previously reported that both the conformational flexibility of the benzyl groups and the formation of various interactions by terminal substituents can be regarded as important factors for the occurrence of polymorphs in unsubstituted- and para-derivatives. ${ }^{[40]}$ Detailed structural analysis of the crystal structures of unsubstituted compounds and the para-derivatives 2-5 further suggested that the terminal substituents on the benzyl groups acted as space-fillers in the thermally stable crystal forms. In contrast, weak interactions such as the $\mathrm{C}-\mathrm{H} \cdots \pi$ and $\mathrm{C}-\mathrm{H} \cdots \mathrm{Cl}$ interactions formed by the terminal substituents largely contributed to the structural stability of the thermally metastable crystal forms. ${ }^{[40]}$ In particular, the derivative with $\mathrm{Cl}$ atoms (derivative 4) exhibited various crystal forms owing to the variety of halogen interactions. These results implied that the halogenated benzyl group can be considered as a structural factor that favours polymorphs in these derivatives. In this study, we analysed the crystal structures of the ortho-X-benzyl derivatives, where $\mathrm{X}=\mathrm{F}$, $\mathrm{Cl}, \mathrm{Br}, \mathrm{I}$, and $\mathrm{Me}$ (derivatives 6-10, Scheme 1), to assess the impact of the terminal halogen substituents on the occurrence of the polymorphs. The derivatives 6, 9, and 10 were newly synthesised and crystallised, before they were subjected to structural and energetical analyses. Even

Title

Role of halogen substituents in a series of polymorphic 2,5-diamino-3,6-dicyanopyrazine derivatives with highly flexible groups $\begin{array}{lll}\text { File Name } & \text { Date } & \text { Page } \\ \text { revised_ortho_Z } & 07.09 .2018 & \text { 2(18) } \\ \text { Krist_1 } & & \end{array}$ 
though the crystal data of derivatives $\mathbf{7}$ and $\mathbf{8}$ have been reported previously, their crystal structures were also subjected to detailed structural and energetical analyses for the very first time in this study. Detailed analysis of the ortho-derivatives' crystal structures (6-10) revealed that the strength of the halogens' electrostatic property plays a significant role in the preferential occurrence of polymorphs in these pyrazine derivatives.

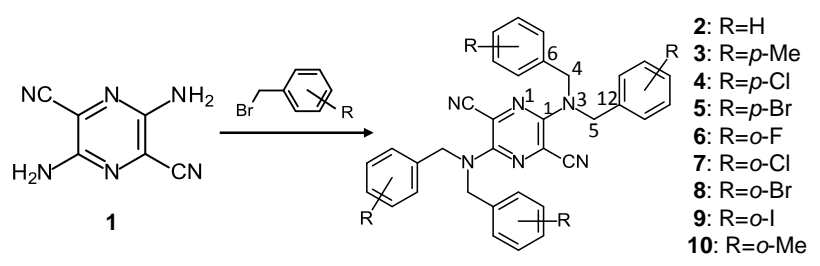

Scheme 1. A series of

2,5-bis( $N, N$-dibenzylamino)-3,6-dicyanopyrazine derivatives.

\section{Experimental}

\subsection{Synthesis}

Derivatives 9-10 were newly synthesised, whereas the other derivatives 6-8 were supplied by Nippon Soda Co. Ltd. The details of the procedure used to synthesise derivatives 6-8 are described in the literature. ${ }^{[36-37]}$ Derivatives 9 and 10 were synthesised using the same procedure as those for derivatives 6-8 (Scheme 1). Compounds 9 and $\mathbf{1 0}$ were characterised by nuclear magnetic resonance (NMR) and infrared (IR) spectroscopies, as well as elemental and X-ray analyses. The details on the synthetic procedure, along with their characterisation data, are described in the supplementary material.

\subsection{Crystallisation of the ortho-derivatives}

The nine crystal forms of derivatives 6-10 were obtained from the use of several solvents at room temperature (Fig. 1). These crystal forms were abbreviated as $6 \mathbf{0}, \mathbf{7 R}, \mathbf{7 Y}$, 8R, 8RO, 8YO, 8Y, 9R, and 10R, where R, RO, O, YO, and $\mathbf{Y}$ represent the colours of the respective crystals: red, reddish orange, orange, yellowish orange, and yellow. The crystallisation process of each crystal form was described in the supplementary material. The solvent conditions by which we obtained the X-ray diffraction quality crystals are shown in Table S1. The crystal structures of 7R, 8R, 8RO, 8YO, and 8Y have been reported previously. ${ }^{[39]}$ The X-ray diffraction measurements were performed on the following three crystal forms: $\mathbf{6 0}, \mathbf{9 R}$, and $\mathbf{1 0 R}$. We could not obtain crystals of $\mathbf{7 Y}$ with sufficient quality for the X-ray diffraction study despite our best efforts in crystallising the compound. 7Y was regarded as another crystal form including solvate other than $\mathbf{7 R}$ because the colour of $7 \mathbf{Y}$ was different from that of $\mathbf{7 R}$. The crystallinity of $\mathbf{7 Y}$ was

Role of halogen substituents in a series of polymorphic 2,5-diamino-3,6-dicyanopyrazine derivatives with highly flexible groups $\begin{array}{lll}\text { File Name } & \text { Date } & \text { Page } \\ \text { revised_ortho_Z } & 07.09 .2018 & 3(18)\end{array}$ 


\section{6}

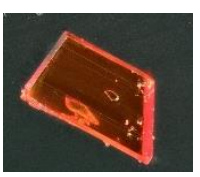

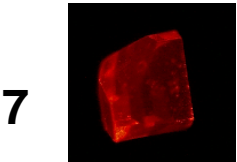

7R

8

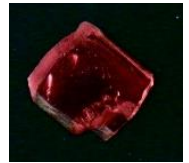

8R

9

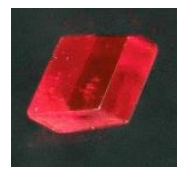

9R

10

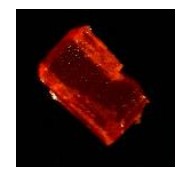

10R

\section{0}

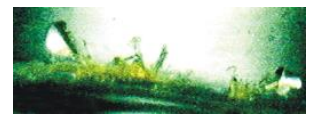

$7 Y$
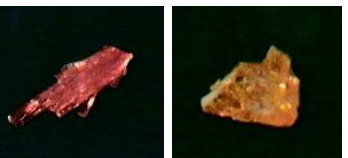

8YO

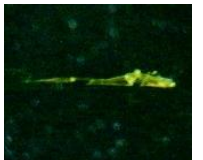

8Y

Fig. 1. Colour-polymorphism of the pyrazine derivatives 6-10.

\subsection{X-ray crystal structure analysis}

The diffraction data for $\mathbf{6 O}$ and $\mathbf{1 0 R}$ were collected at 296

$\mathrm{K}$ on a Rigaku R-AXIS Rapid imaging plate area detector with graphite-monochromated $\mathrm{Cu} K \alpha$ radiation $(\lambda=$ $1.54187 \AA$ ). For $9 R$, the data were collected at $298 \mathrm{~K}$ on a Rigaku AFC-7R diffractometer (equipped with a mercury CCD) with graphite-monochromated Mo $K \alpha$ radiation $(\lambda=$ $0.71075 \AA$ ) as the derivative 9 contains iodine atoms. The numerical absorption correction of 60 and $9 R$ was applied using the RAPID-AUTO ${ }^{[41]}$ and CrystalClear ${ }^{[42]}$ software, respectively. Meanwhile, the absorption correction of $\mathbf{1 0 R}$ was performed via multi-scan using the RAPID-AUTO software.

The structure of 60 was solved using the SHELXS-97 software ${ }^{[43]}$ while those of $\mathbf{9 R}$ and $\mathbf{1 0 R}$ were solved using the SIR2004 software. ${ }^{[4]}$ The structure refinement of all three crystal forms was performed using SHELXL-97. ${ }^{[43]}$ All non-hydrogen atoms were anisotropically refined by full-matrix least-squares refinement based on $F^{2}$. The hydrogen atoms in the three crystal forms were located at the calculated positions and refined using the riding model. All calculations pertaining to structural determination were performed using the CrystalStructure 4.0 software. ${ }^{[45]}$ The Oak Ridge Thermal Ellipsoid Plot (ORTEP) diagram for

Author

Yoko AkuneI, Risa HirosawaI, Atsushi

KosekiI, Shinya

Matsumoto*,I
Title

Role of halogen substituents in a series of polymorphic 2,5-diamino-3,6-dicyanopyrazine derivatives with highly flexible groups
File Name

revised_ortho_Z $\quad 07.09 .2018$

Page

Krist_1 
each crystal form was drawn with $50 \%$ ellipsoid probability using the Mercury 3.5.1 software. ${ }^{[46]}$

\subsection{Observation of thermal phase transition}

The phase transitions between polymorphs were observed using a Mettler FP2 hot stage. Each crystal form was placed on a microscope slide and set on the hot stage. The heating rate was $10 \mathrm{~K} / \mathrm{min}$. The temperature range of the hot stage measurement was $35-205^{\circ} \mathrm{C}$ for $\mathbf{8 R}, 50-205^{\circ} \mathrm{C}$ for $\mathbf{8 R O}$, $50-205^{\circ} \mathrm{C}$ for $\mathbf{8 Y O}, 40-205^{\circ} \mathrm{C}$ for $\mathbf{8 Y}$, respectively. Differential scanning calorimetry (DSC) was performed using a Rigaku Thermo Plus DSC8230 instrument at a heating rate of $10 \mathrm{~K} / \mathrm{min}$. The initial temperature of the DSC measurement was under $40^{\circ} \mathrm{C}\left(25\right.$ to $\left.38^{\circ} \mathrm{C}\right)$, and the final temperature was $160^{\circ} \mathrm{C}$ for $6 \mathrm{O}, 220^{\circ} \mathrm{C}$ for $7 \mathrm{R}, 8 \mathrm{RO}$, and $\mathbf{8 R}, 250^{\circ} \mathrm{C}$ for $9 R$ and $10 R$, respectively.Before undergoing the DSC measurement, each powder sample was characterised by powder X-ray diffraction using glass capillary (Fig. S1). The analysis was carried out using the same equipment and settings (i.e., Rigaku R-AXIS Rapid system) as those used for the single crystal X-ray diffraction study.

\subsection{Conformational analysis}

The evaluation of conformational similarity was carried out using procedures that have been applied to para-derivatives from a previous study ${ }^{[40]}$ In brief, the similarity between two molecular conformations was gauged using the root mean square deviation's (RMSD) value of the distance between each of the pairs of equivalent atoms in two conformations as calculated by the Molecule Overlay module of the Mercury 3.5.1 software. When the RMSD value between two conformations was less than $1 \AA$, the conformations are considered to be similar.

We estimated the pyramid cone angle, defined as the sum of the three angles around the amino nitrogen, to determine whether the amino geometry is trigonal or tetrahedral. In our previous statistical study on the amio geometry of the dibenzylamino group, the amino gemetry whose pyramid cone angle is larger than $348^{\circ}$ was characterised as $\mathrm{sp}^{2}$-like hybridisation. ${ }^{[40]}$ Thus, we characterised the amino geometry using $348^{\circ}$ in this study.

The conformation energies between the polymorphs in derivative 8 were calculated by the Gaussian $09^{[47]}$ software, using the $\omega \mathrm{B} 97 \mathrm{X}-\mathrm{D}$ functional ${ }^{[48]}$ and $6-31 \mathrm{G}(\mathrm{d})$ basis set for all atoms except for the $\mathrm{Br}$ atom, which used LanL2DZ[49]. The positions of the non-hydrogen atoms were based on the atomic coordinates obtained by X-ray analysis. The positions of the hydrogen atoms were normalised in the calculations. Additionally, the Connolly surface area was estimated using the MSMS 2.5.7 $7^{[50]}$ software based on the atomic coordinates of the optimised conformations.

Title

Role of halogen substituents in a series of polymorphic 2,5-diamino-3,6-dicyanopyrazine derivatives with highly flexible groups $\begin{array}{lll}\text { File Name } & \text { Date } & \text { Page } \\ \text { revised_ortho_Z } & \text { 07.09.2018 } & \text { 5(18) }\end{array}$ 


\subsection{Evaluation of intermolecular interactions}

Intermolecular interactions in the observed crystal structures were evaluated through short contact evaluation, lattice energy estimation by the atom-atom Coulomb-London-Pauli (AA-CLP) model, ${ }^{[51]}$ and Hirshfeld surface analysis. ${ }^{[52]}$ The positions of the non-hydrogen atoms were based on the atomic coordinates obtained by $\mathrm{X}$-ray analysis. Meanwhile, the positions of hydrogen atoms were corrected using the averaged value from the neutron diffraction measurements which was provided by Mercury 3.5.1 software. The short contacts are defined as intermolecular interactions that are shorter than the sum of the van der Waals radii. For the AA-CLP model, we used the atomic point charge calculated by the natural population analysis of the Gaussian 09 software; utilising the $\omega \mathrm{B} 97 \mathrm{X}-\mathrm{D}$ functional and 6-31G(d) basis set for all atoms except $\mathrm{Br}$ and I, which used LanL2DZ instead.

\subsection{A series of polymorphic halogenated compounds in the Cambridge Structure Database}

We searched the Cambridge Structure Database (CSD: version 5.36) using ConQuest ${ }^{[53]}$ to explore polymorphic halogenated compounds, which have four halogenated derivatives ( $\mathrm{F}, \mathrm{Cl}, \mathrm{Br}$, and I derivatives), with one or more of all four derivatives exhibiting polymorphism. This search was restricted to compounds containing elemental H/D, B, C, N, O, S, P, and halogens. Compounds with known 3D coordinates were included in the search, whereas polymeric compounds, ions, and multi-component crystals were excluded. Crystal structures determined by powder patterns were also excluded. Polymorphism in the searched compounds was determined by the following steps. First, polymorphism of the search compounds was sorted by CCDC refcode. Second, structural data with the same refcode were compared using the Crystal Packing Similarity module of the Mercury 3.5.1 software. Finally,we identified the polymorphic compound when the number of matched molecules of the compared molecule cluster (cluster size: 15 molecules) in the two crystal structures is less than 15 .

\section{Results and discussion}

The structures of the three novel crystal forms $60,9 R$, and

10R were solved by single crystal X-ray diffraction analysis. The crystal data, including the five previously reported structures $^{[39]}-\mathbf{7 R}, \mathbf{8 R}, \mathbf{8 R O}, \mathbf{8 Y O}$, and $\mathbf{8 Y}$, are summarised in Table 1. All the molecules of the eight crystal forms belonging to the ortho-derivatives occupied a centrosymmetric crystalline position, indicating the presence of half a molecule in the asymmetric unit. The crystal structures of 7R, 8RO, and 10R would show isomorphism based on the similarity in the lattice groups $\begin{array}{lll}\text { File Name } & \text { Date } & \text { Page } \\ \text { revised_ortho_Z } & 07.09 .2018 & 6(18)\end{array}$ 
parameters. The crystal structures of $\mathbf{8 Y O}$ and $\mathbf{9 R}$ would belong to another isomorphic group apart from 7R, 8RO, and 10R.

Table 1. Crystallographic information on the analysed forms of derivatives 6-10.

\begin{tabular}{|c|c|c|c|c|c|c|c|c|}
\hline $\begin{array}{l}\text { Crystal } \\
\text { forms }\end{array}$ & 60 & $7 \mathbf{R}^{\mathrm{a}}$ & $8 \mathbf{R}^{\mathrm{a}}$ & $8 \mathrm{RO}^{\mathrm{a}}$ & $8 Y^{a}$ & $8 Y^{a}$ & 9R & $10 R$ \\
\hline Formula & $\mathrm{C}_{34} \mathrm{H}_{24} \mathrm{~N}_{6} \mathrm{~F}_{4}$ & $\mathrm{C}_{34} \mathrm{H}_{24} \mathrm{~N}_{6} \mathrm{Cl}_{4}$ & $\mathrm{C}_{34} \mathrm{H}_{24} \mathrm{~N}_{6} \mathrm{Br}_{4}$ & $\mathrm{C}_{34} \mathrm{H}_{24} \mathrm{~N}_{6} \mathrm{Br}_{4}$ & $\mathrm{C}_{34} \mathrm{H}_{24} \mathrm{~N}_{6} \mathrm{Br}_{4}$ & $\mathrm{C}_{34} \mathrm{H}_{24} \mathrm{~N}_{6} \mathrm{Br}_{4}$ & $\mathrm{C}_{34} \mathrm{H}_{24} \mathrm{~N}_{6} \mathrm{I}_{4}$ & $\mathrm{C}_{38} \mathrm{H}_{36} \mathrm{~N}_{6}$ \\
\hline $\begin{array}{l}\text { Formula } \\
\text { weight }\end{array}$ & 592.60 & 658.42 & 836.22 & 836.22 & 836.22 & 836.22 & 1024.22 & 576.74 \\
\hline $\begin{array}{l}\text { Space } \\
\text { group }\end{array}$ & $P \overline{1}$ & $P 2_{1} / n$ & $P \overline{1}$ & $P 2_{1} / n$ & $P \overline{1}$ & $P \overline{1}$ & $P \overline{1}$ & $P 2_{1} / n$ \\
\hline $\begin{array}{l}\text { Radiation } \\
\text { type }\end{array}$ & $\mathrm{Cu} K \alpha$ & $\mathrm{Cu} K \alpha$ & $\mathrm{CuK \alpha}$ & $\mathrm{Cu} K \alpha$ & $\mathrm{CuK \alpha}$ & $\mathrm{CuK \alpha}$ & $\operatorname{MoK\alpha }$ & $\mathrm{CuK \alpha}$ \\
\hline$T(\mathrm{~K})$ & 296 & 296 & 296 & 296 & 296 & 296 & 298 & 296 \\
\hline$a(\AA)$ & $6.8045(1)$ & $12.659(3)$ & $8.013(3)$ & $12.831(2)$ & $7.6207(9)$ & $8.55(4)$ & $7.745(3)$ & $12.803(3)$ \\
\hline$b(\AA)$ & $9.9620(2)$ & $7.070(2)$ & $9.204(4)$ & 7.241(1) & $10.209(2)$ & $10.05(3)$ & $10.466(4)$ & $7.199(2)$ \\
\hline$c(\AA)$ & $10.9299(2)$ & $18.362(5)$ & $11.328(5)$ & 17.990(1) & $11.121(1)$ & $10.93(7)$ & $11.102(5)$ & $17.926(4)$ \\
\hline$\alpha\left(^{\circ}\right)$ & $97.8679(7)$ & 90 & $77.00(2)$ & 90 & $79.85(1)$ & $103.5(2)$ & 81.92(1) & 90 \\
\hline$\beta\left(^{\circ}\right)$ & $97.6059(7)$ & $108.45(2)$ & $87.33(2)$ & $108.516(5)$ & $84.07(2)$ & $107.3(3)$ & $84.16(1)$ & $107.91(2)$ \\
\hline$\gamma\left({ }^{\circ}\right)$ & ${ }^{103.0509(7}$ & 90 & $80.09(3)$ & 90 & $71.51(1)$ & $112.8(5)$ & 71.772(9) & 90 \\
\hline$Z$ & 1 & 2 & 1 & 2 & 1 & 1 & 1 & 2 \\
\hline$V\left(\AA^{3}\right)$ & $704.65(3)$ & $1558.9(7)$ & $801.8(6)$ & $1584.9(4)$ & $806.6(2)$ & $758.7(6)$ & $844.6(6)$ & $1572.2(6)$ \\
\hline $\begin{array}{l}D_{\text {calc }} \\
\left(\mathrm{g} / \mathrm{cm}^{3}\right)\end{array}$ & 1.396 & 1.403 & 1.732 & 1.752 & 1.721 & 1.830 & 2.013 & 1.218 \\
\hline$F(000)$ & 306 & 676 & 410 & 820 & 410 & 410 & 482 & 612 \\
\hline$\mu\left(\mathrm{mm}^{-1}\right)$ & 0.866 & 3.730 & 6.403 & 6.479 & 6.365 & 6.767 & 3.724 & 0.570 \\
\hline $\begin{array}{l}\text { No. of } \\
\text { reflns } \\
\text { collection }\end{array}$ & 9896 & 11414 & 7268 & 14411 & 7769 & 6981 & 6578 & 11127 \\
\hline $\begin{array}{l}\text { No. of } \\
\text { unique } \\
\text { reflns } \\
\text { /parameters }\end{array}$ & $2375 / 200$ & $2604 / 212$ & $2646 / 212$ & $2851 / 211$ & $2691 / 212$ & $2495 / 211$ & $3804 / 199$ & $2772 / 199$ \\
\hline$R_{1} / \mathrm{w} R_{2}$ & $\begin{array}{l}0.0631 / \\
0.1795\end{array}$ & $\begin{array}{l}0.0572 / \\
0.0917\end{array}$ & $\begin{array}{l}0.0710 / \\
0.1540\end{array}$ & $\begin{array}{l}0.0390 / \\
0.0570\end{array}$ & $\begin{array}{l}0.0610 / \\
0.0810\end{array}$ & $\begin{array}{l}0.0550 / \\
0.1280\end{array}$ & $\begin{array}{l}0.0644 / \\
0.1769\end{array}$ & $\begin{array}{l}0.0452 / \\
0.1090\end{array}$ \\
\hline GOF & 1.215 & 1.056 & 1.369 & 1.222 & 0.939 & 0.816 & 0.973 & 0.999 \\
\hline
\end{tabular}

${ }^{a}$ The crystal structures of 7R, 8R, 8RO, 8YO, and $8 Y$ were published previously [39].

\subsection{The thermal stability between the polymorphs}

The most thermally stable crystal form of each derivative was determined by thermal analysis. For derivative 7 , which presumably has two polymorphs, 7R did not transform into any other forms as determined by DSC (Fig. S2). Although the thermal analysis of $\mathbf{7 Y}$ could not be carried out owing to the unavailability of its crystals, $7 \mathbf{R}$ was presumably more stable than $\mathbf{7 Y}$ at room temperature. For derivative $\mathbf{8}$ that has four forms, all four forms were subjected to hot stage measurement, while the DSC

Title

Role of halogen substituents in a series of polymorphic 2,5-diamino-3,6-dicyanopyrazine derivatives with highly flexible groups $\begin{array}{lll}\text { File Name } & \text { Date } & \text { Page } \\ \text { revised_ortho_Z } & 07.09 .2018 & 7(18)\end{array}$ Krist_1 
measurement was carried out only for $\mathbf{8 R}$ and $\mathbf{8 R O}$. An adequate amount of $\mathbf{8 Y}$ and 8YO's crystals could not be obtained for the DSC measurement. During the hot stage measurement, the crystal of $\mathbf{8 Y}$ transformed into $\mathbf{8 R}$ and/or 8RO in the temperature range between 90.5 and $101.8^{\circ} \mathrm{C}$. Similarly, the crystal of $\mathbf{8 Y O}$ transformed into $\mathbf{8 R}$ and/or 8RO between 172.6 and $178.5^{\circ} \mathrm{C}$. We did not observe the transformations of $\mathbf{8 R}$ and $\mathbf{8 R O}$ even at their respective melting points during the hot stage and DSC measurements. To clarify the thermal relationship between $\mathbf{8 R}$ and $\mathbf{8 R O}$, the transition point was calculated using the melting point data of these two crystal forms according to the method reported by $\mathrm{Yu}^{\left[{ }^{[5]}\right]}$ The result indicated that the thermal relationship between $\mathbf{8 R}$ and $\mathbf{8 R O}$ was monotropic, with 8RO being the thermally stable form (Table S2 and experimental section 3 of the supplementary material). Moreover, the result of the calculated total crystal energies, defined as the sum of the relative conformational and lattice energies, supported the observation that the energy of 8RO was the lowest among the four polymorphs of derivative $\mathbf{8}$ (Table S3).

We could not obtain any polymorphs of the derivatives $\mathbf{6 , 9}$, and 10 despite our attempts to crystallise them. No phase transitions of 6O, 9R, and 10R were observed even upon reaching their melting points during the DSC measurement (Fig. S2). As a result, these three crystal forms can be regarded as the thermally stable forms.

\subsection{Conformational analysis}

In our previous study, ${ }^{[39]}$ the molecular conformation in the crystal structures had a similarity in the amino geometry among crystal forms with the same crystal colour (yellow or red and orange) despite of the difference in the terminal substituents of the benzyl groups: the yellow crystal forms have tetrahedral amino geometries, whereas the red and orange crystal forms have trigonal amino geometries. A similar trend was also found for the ortho-derivatives. The conformations of the eight crystal forms in derivatives 6-10 were divided into three groups based on their conformational similarities (Groups I-III) (Fig. 2 and Table S4). Group I has five crystal forms: 6O, 7R, 8R, 8RO, and 10R. The amino groups of all five forms have trigonal geometries according to their calculated pyramid cone angles, which are defined as the sum of the three angles around the amino group (Table 2). Meanwhile, Group II includes two crystal forms: 8YO and 9R. The amino groups of $8 Y O$ and $9 R$ have trigonal geometries despite being conformationally different from the members of Group I (Table 2). Group III constitutes of only $\mathbf{8 Y}$ and its conformation is quite different from the conformations of other ortho-derivatives. The amino group has near-trigonal geometry (the pyramid cone angle: $350.1^{\circ}$ ). This result suggested that the flexibility of the dibenzylamino group facilitates the occurrence of polymorphs in the ortho-derivatives as the conformational energy surface would also have several potential wells in the ortho-derivatives.

Compared to the para-derivatives 3-5, the conformations of

Author

Yoko AkuneI, Risa HirosawaI, Atsushi KosekiI, Shinya Matsumoto*,I
Title

Role of halogen substituents in a series of polymorphic 2,5-diamino-3,6-dicyanopyrazine derivatives with highly flexible groups $\begin{array}{lll}\text { File Name } & \text { Date } & \text { Page } \\ \text { revised_ortho_Z } & 07.09 .2018 & 8(18)\end{array}$

Krist_1 
Groups I and II in the ortho-derivatives were observed in the para-derivatives, respectively. ${ }^{[40]}$ In contrast, the conformation of Group III was distinctive among all the ortho- and para-derivatives. Additionally, the conformations of the thermally stable form in the para-derivatives were not observed in the ortho-derivatives. This result implied that the position of the terminal substituents had an impact on the conformational potential surface. The conformations of Groups I and II were relatively stable in a crystalline state, while the other conformations were sensitive to the position of the terminal substituents.

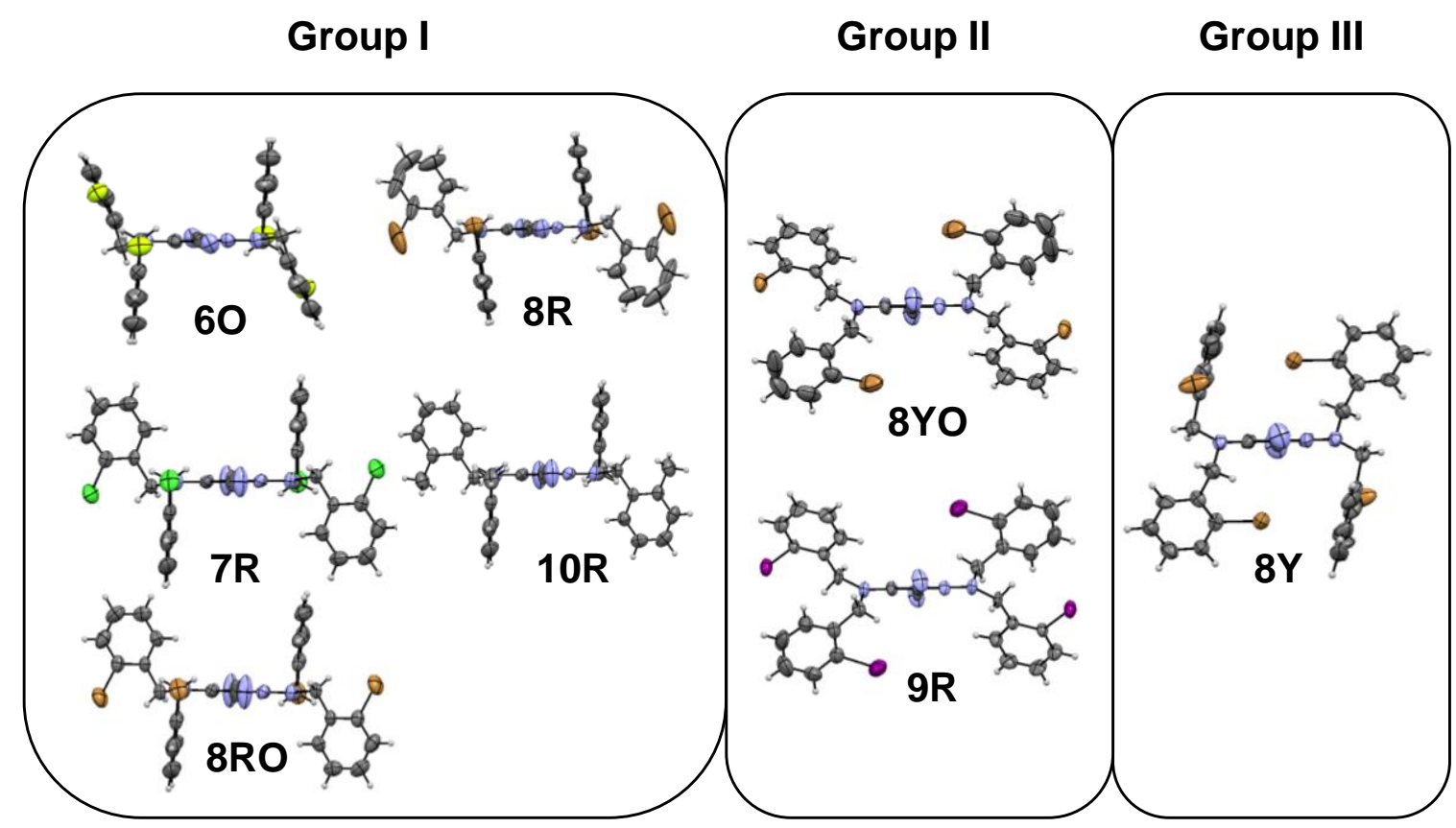

Fig. 2. Conformational similarities of derivatives 6-10. The eight conformations were divided into three groups (Groups I-III).

Table 2. Significant molecular geometries of amino groups in the ortho-derivatives.

$\begin{array}{cllllll} & \begin{array}{l}\text { Bond } \\ \text { length/A }\end{array} & \begin{array}{l}\text { Calculated } \\ \text { angle }{ }^{\circ} \\ \text { Pyramid } \\ \text { cone } \\ \text { angle }^{\mathrm{a}}\end{array} & \begin{array}{l}\text { N1-C1-N3 } \\ \text { C1-N3 }\end{array} & \begin{array}{l}\text { N1-C1-N3 } \\ \text { C1-N3-C4 }\end{array} & \begin{array}{l}\text { C1-N3-C5 } \\ \text { Torsion angles/ }\end{array} \\ \mathbf{6 O} & 1.370(7) & 359.6 & 9.1(7) & -178.5(5) & 75.8(6) & 87.7(6) \\ \mathbf{7 R} & 1.367(3) & 359.8 & 8.4(2) & -177.4(2) & 87.6(2) & 102.9(2) \\ \mathbf{8 R} & 1.369(6) & 359.9 & 7.4(7) & -175.4(5) & 84.8(6) & 112.7(6) \\ \mathbf{8 R O} & 1.372(4) & 359.7 & 6.7(5) & -179.8(3) & 86.6(4) & 104.1(4) \\ \mathbf{8 Y O} & 1.38(1) & 357.4 & 29.3(8) & -131.7(6) & 114.5(7) & 128.6(6) \\ \mathbf{8 Y} & 1.36(2) & 350.1 & 30(1) & -114(1) & 60(1) & 81(1) \\ \mathbf{9 R} & 1.38(1) & 358.6 & 29(1) & -137.8(7) & 121.4(8) & 124.1(7) \\ \mathbf{1 0 R} & 1.361(2) & 359.6 & 6.7(2) & 179.4(1) & 84.9(2) & 108.6(2)\end{array}$

a The pyramid cone angle was defined as the sum of the three angles around the amino nitrogen: C1-N3-C5, C1-N3-C4, and C4-N3-C5.

Role of halogen substituents in a series of polymorphic 2,5-diamino-3,6-dicyanopyrazine derivatives with highly flexible groups 


\subsection{Isomorphism of thermally stable crystal forms of the $\mathrm{Cl}, \mathrm{Br}$, and $\mathrm{Me}$ derivatives}

The crystal structures of the three thermally stable crystal forms, $\mathbf{7 R}, \mathbf{8 R O}$, and $\mathbf{1 0 R}$, were found to exhibit isomorphism. The energy of the interactions between two molecules (a molecular pair) in the crystal structures was calculated using the AA-CLP model. For the three stable forms of the ortho-derivatives, the molecular pair that includes the packing of the benzyl groups along the $a$-axis has the largest contribution to their lattice energies (Table 3). In this molecular pair, $\mathrm{C}-\mathrm{H} \cdots \pi / \mathrm{C}$ interactions were observed based on the short contacts (Fig. 3a). The molecular pairs along the $b$-axis, which includes chromophore stacking, has the second-largest contribution among the three crystal forms (Fig. 3b).

For the crystal structures of the halogenated derivatives, $7 \mathbf{R}$ and $\mathbf{8 R O}$, the interactions between halogen atoms found in the molecular pairs are related by the following symmetry operations: $1+x, 1+y, z$ and $-1+x,-1+y, z$ (Fig. 3c). These molecular pairs, connected by halogen interactions, are centrosymmetric dimers and the angles of C-X $\cdots \mathrm{X}-\mathrm{C}$ in $\mathbf{7} \mathbf{R}$ and $\mathbf{8 R O}$ are $177.60(7)^{\circ}$ and $176.7(1)^{\circ}$ respectively (Table S5). Thus, the halogen interactions are classified as a Type I geometry, which is regarded as a space-filling type. ${ }^{[55]}$ The centrosymmetric dimers of $\mathbf{7 R}$ and $\mathbf{8 R O}$ were found to have a low contribution rate to their lattice energy (Table S5). This result suggested that $\mathbf{7 R}$ and $\mathbf{8 R O}$ have closed-packing crystal structures. The crystal structure of 10R was regarded as closed packing structure, although the hydrogen of the terminal methyl groups interacts with the $\pi$-electron of the phenyl ring that is part of the benzyl moiety packed along the $a$-axis based on the short contacts (Fig. 3a). The difference in the occurrence of the polymorphs between derivatives with halogen atoms ( 7 and 8), which exhibited polymorphs, and the derivative with methyl groups (10), which did not, might be correlated with the ability of substituent to form intermolecular interactions such as halogen bonding which stabilised the metastable forms (see section 3.4 for details)..

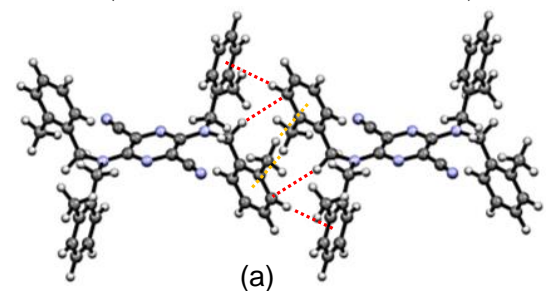

(a)

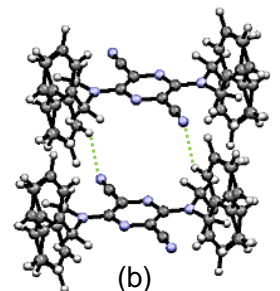

(b)

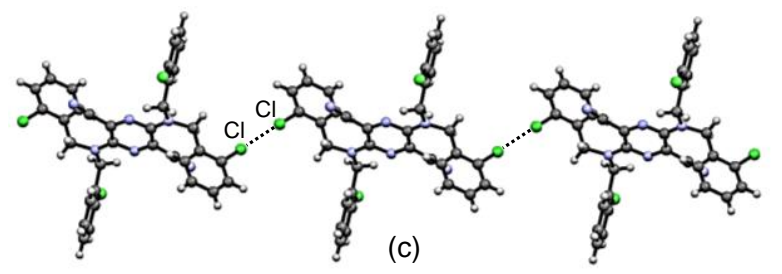

Fig. 3. The crystal structures of the isomorphic group in the thermally stable forms $-\mathbf{7 R}, \mathbf{8 R O}$, and 10R. (a) The molecular pair with the largest energy contribution to the lattice energy along the $a$-axis. The common $\mathrm{C}-\mathrm{H} \cdots \mathrm{C} / \pi$ interactions among the benzyl groups in the three crystal forms are represented by the red dashed

Title

Role of halogen substituents in a series of polymorphic 2,5-diamino-3,6-dicyanopyrazine derivatives with highly flexible groups $\begin{array}{lll}\text { File Name } & \text { Date } & \text { Page } \\ \text { revised_ortho_Z } & 07.09 .2018 & 10(18)\end{array}$ Krist_1 
lines. The orange dashed lines represent the $\mathrm{C}-\mathrm{H} \cdots \pi$ interactions, which were observed only in the crystal structure of 10R. (b) The molecular pair with the second largest energy contribution along the $b$-axis. The molecular pairs in the crystal structures of $7 \mathbf{R}$ and 10R that are involved in the $\mathrm{C}-\mathrm{H} \cdots \mathrm{N}$ interactions are represented by the green dashed lines. (c) The halogen interactions,

represented by the black dashed lines, were observed in the crystal structures of $\mathbf{7 R}$ and $\mathbf{8 R O}$.

Table 3. Significant molecular geometries of the ortho-derivatives.

\begin{tabular}{|c|c|c|c|c|c|}
\hline & \multirow[b]{2}{*}{$\begin{array}{l}\text { Total pair } \\
\text { energy } \\
{[\mathrm{kcal} / \mathrm{mol}]}\end{array}$} & \multicolumn{4}{|c|}{ The energy of a molecular pair } \\
\hline & & $\begin{array}{l}\text { Most } \\
\text { stable pair } \\
{[\mathrm{kcal} / \mathrm{mol}]}\end{array}$ & $\begin{array}{l}\text { Symmetry } \\
\text { operation }\end{array}$ & $\begin{array}{l}2^{\text {nd }} \text { stable } \\
\text { pair } \\
{[\mathrm{kcal} / \mathrm{mol}]}\end{array}$ & $\begin{array}{l}\text { Symmetry } \\
\text { operation }\end{array}$ \\
\hline 60 & -94.7 & $\begin{array}{l}-10.5 \\
(11.1 \%)\end{array}$ & $x, \pm 1+y, z$ & $\begin{array}{l}-9.92 \\
(10.5 \%)\end{array}$ & $\pm 1+x, y, z$ \\
\hline $7 \mathbf{R}$ & -106.3 & $\begin{array}{l}-11.6 \\
(10.9 \%)\end{array}$ & $\pm 1+x, y, z$ & $\begin{array}{l}-10.9 \\
(10.3 \%)\end{array}$ & $x, \pm 1+y, z$ \\
\hline 8R & -104.4 & $\begin{array}{l}-12.2 \\
(11.7 \%)\end{array}$ & $x, \pm 1+y, z$ & $\begin{array}{l}-9.25 \\
(8.86 \%)\end{array}$ & $\pm 1+x, y, z$ \\
\hline 8RO & -115.1 & $\begin{array}{l}-12.6 \\
(10.9 \%)\end{array}$ & $\pm 1+x, y, z$ & $\begin{array}{l}-11.8 \\
(10.3 \%)\end{array}$ & $x, \pm 1+y, z$ \\
\hline $8 Y O$ & -101.6 & $\begin{array}{l}-13.2 \\
(13.1 \%)\end{array}$ & $\pm 1+x, y, z$ & $\begin{array}{l}-12.5 \\
(12.3 \%)\end{array}$ & $x, \pm 1+y, z$ \\
\hline $8 Y$ & -101.1 & $\begin{array}{l}-11.4 \\
(11.3 \%)\end{array}$ & $x, \pm 1+y, z$ & $\begin{array}{l}-10.6 \\
(10.5 \%)\end{array}$ & $x, y, \pm 1+z$ \\
\hline 9R & -108.8 & $\begin{array}{l}-13.6 \\
(12.5 \%)\end{array}$ & $x, \pm 1+y, z$ & $\begin{array}{l}-13.4 \\
(12.3 \%)\end{array}$ & $\pm 1+x, y, z$ \\
\hline $10 R$ & -106.3 & $\begin{array}{l}-10.7 \\
(10.1 \%)\end{array}$ & $\pm 1+x, y, z$ & $\begin{array}{l}-10.4 \\
(9.82 \%)\end{array}$ & $x, \pm 1+y, z$ \\
\hline
\end{tabular}

${ }^{a}$ Total pair energy represents the sum of the energies of all the calculated molecular pairs. A half-value of the total energy corresponds to the lattice energy.

\subsection{Polymorphic derivative involving $\mathrm{Br}$}

The derivative $\mathbf{8}$ exhibits four crystal forms $-\mathbf{8 R}, \mathbf{8 R O}$,

8YO, and $8 Y$ with different colours. The crystal structures of the metastable forms, $\mathbf{8 R}, \mathbf{8 Y O}$, and $\mathbf{8 Y}$, are quite different from that of the thermally stable form (8RO). The various halogen interactions could be identified in the crystal structure of each metastable form. The energy analysis revealed that the molecular pairs, which include the halogen interactions, have a large impact on the lattice energies of all the metastable forms but not that of the stable form (Table S5). In other words, the structural stabilities of the metastable forms correlated with the intermolecular interactions that are formed by the orthosubstituents. The results of the ortho-derivatives are consistent with those of the para-derivatives even though the halogen interactions in the metastable forms of the ortho-derivatives are different from those in the para-derivatives. ${ }^{[40]}$ Fig. 4 shows the major halogen interactions occurring in the crystal structures of the three metastable forms of derivative $\mathbf{8}$.

In the crystal structure of $\mathbf{8 R}$, the molecular pair in the arrangement along the $a$-axis formed $\mathrm{C}-\mathrm{Br} \cdots \mathrm{N}$ and $\mathrm{C}-\mathrm{H} \cdots \mathrm{Br}$ interactions (Table S5). The acceptor site in the $\mathrm{C}-\mathrm{Br} \cdots \mathrm{N}$ interaction is the nitrogen atom of the pyrazine ring (Fig. 4a). This type of halogen bonding involving the

Author

Yoko AkuneI, Risa HirosawaI, Atsushi

KosekiI, Shinya

Matsumoto*,I
Title

Role of halogen substituents in a series of polymorphic 2,5-diamino-3,6-dicyanopyrazine derivatives with highly flexible groups $\begin{array}{lll}\text { File Name } & \text { Date } & \text { Page } \\ \text { revised_ortho_Z } & 07.09 .2018 & 11(18)\end{array}$ 
pyrazine nitrogen was only observed in the crystal structure of $\mathbf{8 R}$ in all the fourteen crystal structures of the ortho- and para-derivatives. In the crystal structure of $\mathbf{8 Y O}, \mathrm{C}-\mathrm{Br} \cdots \mathrm{N}$ interactions were also found in the molecular pair

(symmetry operation: $-1+x, 1+y, z$ and $1+x,-1+y,-z$ ). The acceptor site in the $\mathrm{C}-\mathrm{Br} \cdots \mathrm{N}$ interaction is the cyano group (Fig. 4b). The interaction between the cyano group and the terminal halogen atom is also present in the crystal structure of $4 Y O$. However, the halogen interactions in $4 Y O$ were observed in chains of molecules,${ }^{[40]}$ whereas the $\mathrm{C}-\mathrm{N} \cdots \mathrm{Br}$ interactions of $\mathbf{8 Y O}$ were observed in molecular dimer, i.e. complementary halogen bonding. These structural analysis results indicated that the difference in the position of the substituents could affect the formation of halogen interactions, especially the cyclic $\mathrm{C}-\mathrm{Br} \cdots \mathrm{N}$ interactions that occur preferentially in the crystal structures of the ortho-derivatives. In addition, the two halogen bonding acceptor sites in the pyrazine derivatives contributed to the variety of packing patterns via the formation of different interaction motifs.

In the crystal structure of $\mathbf{8 Y}$, a molecular pair that includes the $\mathrm{Br} \cdots \mathrm{Br}$ interactions, characterised as Type I, was found and this interaction is similar to that observed in the stable form (Fig. 4c). However, this molecular pair of $\mathbf{8 Y}$ contributed significantly to the lattice energy as opposed to that of the stable form. Additionally, $\mathrm{C}-\mathrm{H} \cdots \mathrm{Br}$ interactions in the crystal structure of $\mathbf{8 Y}$ were found, where the molecular pair showing $\mathrm{C}-\mathrm{H} \cdots \mathrm{Br}$ interactions makes a relatively large contribution to the lattice energy (Table S5). Hirshfeld surface analysis indicated that the contribution of halogen interactions in $\mathbf{8 Y}$ is lower than those of the other polymorphs in derivative 8 (Fig. 5). This result is attributed to the small molecular surface area of $\mathbf{8 Y}$ in comparison to those of the other polymorphs of derivative 8 (Table S3). The conformation with a small surface area favoured the formation of intramolecular interactions. ${ }^{[56]}$ Indeed, intramolecular interactions between the terminal substituents and the carbon in the phenyl or pyrazine ring (Fig. S3) were found in the conformation of $\mathbf{8 Y}$ because the $\mathrm{Br}$ atoms relatively pointed inward side of the molecule in 8Y. Thus, we could conclude that halogen interactions also play an important role in the crystal structure of $\mathbf{8 Y}$. Based on the structural analysis of the thermally metastable crystal forms, it is evident that the interactions formed by the terminal substituents stabilise the crystal structures of the metastable forms of the ortho-derivatives. The variety of halogen interactions brought about the stabilisation in several metastable forms of derivative $\mathbf{8}$. groups 

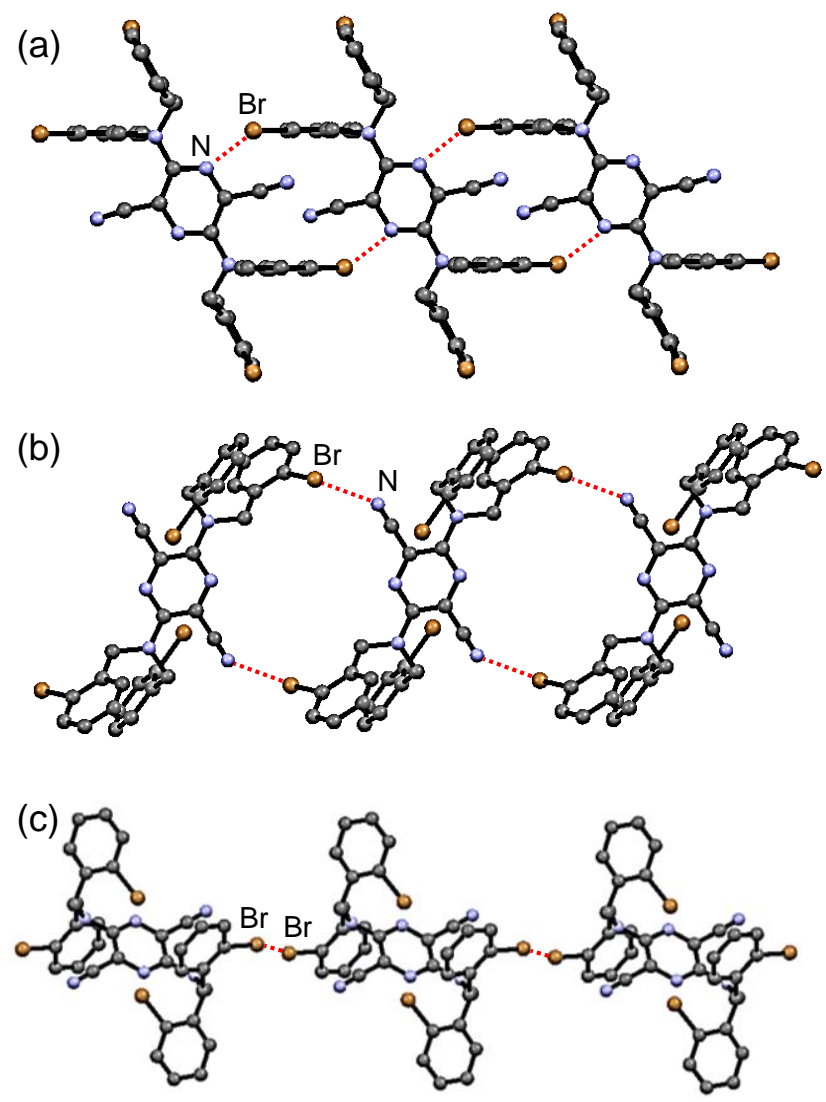

Fig. 4. The crystal structures of the metastable forms of derivative 8. (a) 8R, (b) 8YO, and (c) 8Y. The halogen interactions are represented by the red dashed lines.

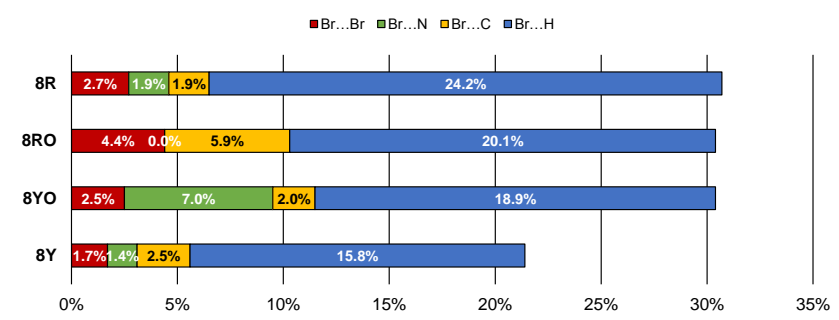

Fig. 5. Relative contribution of the halogen interactions to the Hirshfeld surface area of the four crystal forms in derivative $\mathbf{8}$.

\subsection{Non-polymorphic derivatives involving $F$ or I}

The structural analysis of the polymorphic pyrazine derivatives with ortho- and para-substituents revealed that the occurrence of the polymorphs required the terminal substituents to form suitable intermolecular interactions, such as halogen interactions. The variety of halogen interactions formed by $\mathrm{Cl}$ and $\mathrm{Br}$ atoms further contributed to the occurrence of two or more metastable forms. In contrast, the ortho-derivatives with F or I atoms did not exhibit polymorphism despite repeated efforts to crystallise them under ambient conditions (see supplementary material). The difficulty in inducing the formation of

Author

Yoko AkuneI, Risa HirosawaI, Atsushi

KosekiI, Shinya

Matsumoto*,I
Title

Role of halogen substituents in a series of polymorphic 2,5-diamino-3,6-dicyanopyrazine derivatives with highly flexible groups 
polymorphs in these two derivatives, when compared to other polymorphic pyrazine derivatives, is probably a result of the terminal substituents' properties such as electronegativity, polarisability, and atomic size. We analysed the crystal structures of 60 and $9 R$ to estimate the effect of terminal substituents on the occurrence of polymorphs.

The crystal structure of $\mathbf{6 0}$ is quite different from the other thermally stable forms $\mathbf{7 R}, \mathbf{8 R O}$, and $\mathbf{1 0 R}$ as many $\mathrm{C}-\mathrm{H} \cdots \mathrm{F}$ interactions were observed (Fig. 6). The molecular pairs that involved $\mathrm{C}-\mathrm{H} \cdots \mathrm{F}$ interactions have the second-largest and third-largest contribution to the lattice energy (Table $\mathrm{S} 5)$. The molecular pair responsible for the largest contribution has no such interactions and this pair is mainly connected by the $\pi-\pi$ stacking of the benzyl ring. The sum of the second- and third-largest contribution rates of the molecular pairs including intermolecular interactions related with halogen is significantly larger than the largest individual contribution rate of the molecular pair including intermolecular interactions related without halogen. As a result, the crystal structure of $\mathbf{6 0}$ is stabilised by the weak hydrogen bond that is induced by the highly electronegative F atom.

The crystal structure of $\mathbf{9 R}$ is isomorphous with that of 8YO, which is the rarely seen metastable form of derivative 8. The C-I $\cdots \mathrm{N}$ interaction was observed between the terminal substituents and the cyano group (Fig. 7). The molecular pairs, including their halogen interaction, have a large contribution to the lattice energy (Table S5). The polarisability of the I atom is the highest among all four halogen atoms. This implied that the formation of C-I $\cdots \mathrm{N}$ interactions would be favoured in the crystal structure of derivative $\mathbf{9}$, as opposed to the closed-packing of the thermally stable forms of 6-8 and $\mathbf{1 0}$.

The results of the structural analysis of derivatives $\mathbf{6}$ and $\mathbf{9}$ indicated that the formation of the relatively strong and directional intermolecular interactions by the terminal substituents has an impact on the stability of the closed-packing structure, which was observed in the thermally stable form of the polymorphic pyrazine derivatives. The stabilisation of these crystal structures is mainly due to the electrostatic interactions involving halogens, 60, and 9R, and it might be correlated to the difficulty in polymorph occurrence in derivatives $\mathbf{6}$ and 9. In other words, the ease of polymorph occurrence depends on achieving an appropriate balance between the energy of the closed-packing structure and that of the crystal structure generated mainly by the electrostatic interactions involving halogens in these pyrazine derivatives.

Title

Role of halogen substituents in a series of polymorphic 2,5-diamino-3,6-dicyanopyrazine derivatives with highly flexible groups $\begin{array}{lll}\text { File Name } & \text { Date } & \text { Page } \\ \text { revised_ortho_Z } & 07.09 .2018 & 14(18)\end{array}$ 


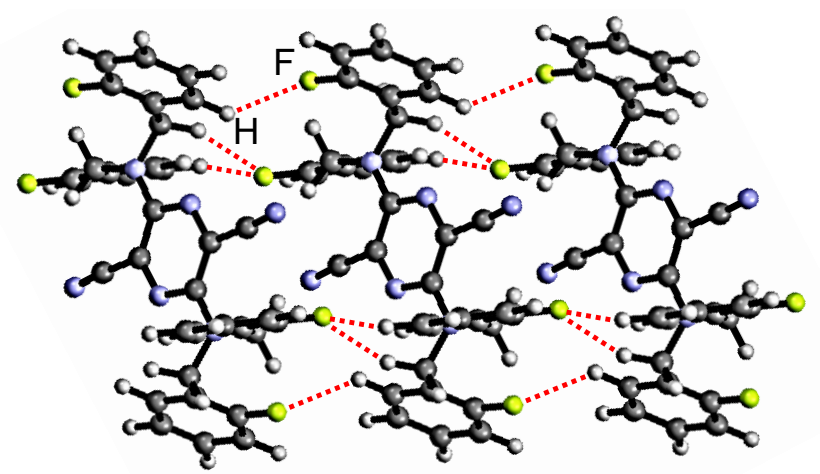

Fig. 6. The crystal structure of 60 .

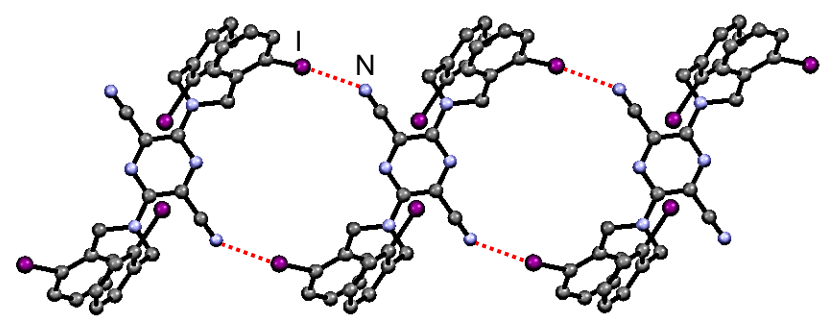

Fig. 7. The crystal structure of $\mathbf{9 R}$.

\subsection{Comparison with polymorphic halogenated compounds in the CSD}

We performed statistical analysis using the CSD to evaluate the effect of halogen atom type on the occurrence of polymorphs in organic compounds. A total of 19 compounds were identified to have four halogenated derivatives ( $\mathrm{F}, \mathrm{Cl}, \mathrm{Br}$, and I derivatives), with one or more of all four derivatives exhibiting polymorphism, in the CSD (Table S6). Among the 19 compounds, derivatives with a $\mathrm{Cl}$ atom was found to be the halogenated species that strongly favours polymorphs. The $\mathrm{Cl}$ derivatives of 10 compounds showed polymorphism out of the 19 compounds (53\%). For the other three halogenated derivatives, the number of non-polymorphic derivatives is larger than that of polymorphic derivatives. The search result is partly consistent with the results of the pyrazine derivatives with ortho-substituents, i.e. $\mathrm{Cl}$ derivative is polymorphic while $\mathrm{F}$ and I derivatives are relatively non-polymorphic. The result of the para-substituted pyrazine derivatives 4-5 is also consistent with the search result, i.e. $\mathrm{Cl}$ derivative (derivative 4 ) is more polymorphic than $\mathrm{Br}$ derivative (derivative 5). In contrast, the result of pyrazine's Br derivative in this study is different from the search result, i.e. Br derivatives generally do not favour polymorphs, whereas the pyrazine dye's Br derivative exhibited four polymorphs. This suggested that the occurrence of polymorphs in a derivative with $\mathrm{Br}$ atom possibly requires the use of special conditions to improve the formation of intermolecular interactions between $\mathrm{Br}$ and other atoms. In the pyrazine derivatives, the substituted position of $\mathrm{Br}$ atoms, which can easily form intermolecular interactions between $\mathrm{Br}$ and $\mathrm{N}$ or $\mathrm{H}$ atoms, would play an

Role of halogen substituents in a series of polymorphic 2,5-diamino-3,6-dicyanopyrazine derivatives with highly flexible groups $\begin{array}{lll}\text { File Name } & \text { Date } & \text { Page } \\ \text { revised_ortho_Z } & 07.09 .2018 & 15(18)\end{array}$ 
important role in the occurrence of various polymorphs. Further studies are required to clarify the general impact of halogen atom on the occurrence of polymorphs because of a small number of searched compounds. In addition, there is the possibility that the compounds of the CSD data had a difference in an effort of polymorph screening.

\section{Conclusions}

In 2,5-diamino-3,6-dicyanopyrazine derivatives with ortho-substituents on the benzyl groups (6-10), in total nine crystal forms were observed, and the structure of eight forms were analysed. Conformational analysis suggested that the conformational flexibility of the dibenzylamino group is suited for the occurrence of conformational polymorphism as their flexibility presumably has several potential wells in the conformational energy surface. Detailed structural analysis revealed that the thermally stable forms of the polymorphic derivatives 7 (with $\mathrm{Cl}$ atoms) and $\mathbf{8}$ (with $\mathrm{Br}$ atoms) have closed-packing characteristics, whereas halogen interactions play an important role in the formation of the various metastable forms. In the case of the thermally stable forms of non-polymorphic derivative $\mathbf{6}$ (with $\mathrm{F}$ atoms) and $\mathbf{9}$ (with I atoms), intermolecular interactions involving halogens stabilised the crystal structures just like in the metastable forms of the other polymorphic pyrazine derivatives. The difficulty of the occurrence of polymorphs in derivative $\mathbf{1 0}$ (with Me groups) where the thermally stable form had the same closed packing structure as the thermally stable forms of $\mathbf{7}$ and $\mathbf{8}$ might be correlated with the ability of substituent to form intermolecular interactions such as halogen bonding which stabilised the metastable forms. This indicated that the ease of polymorph occurrence would require an appropriate balance between the crystal energy of the closed-packing structure and that of the crystal structure generated mainly by the electrostatic interactions involving halogens in these halogenated pyrazine derivatives. Statistical analyses involving the polymorphic halogenated compounds listed in the CSD indicated that the $\mathrm{Br}$ derivative 8 belongs to a relatively non-polymorphic group among the four halogenated derivatives. The difference between the statistical result and the experimental result of the pyrazine derivatives suggested that a suitable substituted position, which can form intermolecular interactions between $\mathrm{Br}$ and other atoms, is also an important factor in the occurrence of polymorphs.

Acknowledgements. The authors thank Dr. Mitsuhiro Yanagita of Nippon Soda Co. Ltd. for the kind provision of a part of the dye samples. The study was supported by the joint research project "Subject C" of the Research Institute of Environment and Information Sciences of Yokohama National University.

\section{References}

[1] J. Bernstein, Polymorphism in Molecular Crystals, Clarendon Press, Oxford, 2002.

[2] G. R. Desiraju, Cryst. Growth Des., 2008, 8, 3.

Title

Role of halogen substituents in a series of polymorphic 2,5-diamino-3,6-dicyanopyrazine derivatives with highly flexible groups $\begin{array}{lll}\text { File Name } & \text { Date } & \text { Page } \\ \text { revised_ortho_Z } & 07.09 .2018 & 16(18)\end{array}$ 
[3] J. Bernstein, A. T. Hagler, J. Am. Chem. Soc., 1978, 100, 673.

[4] L. Yu, S. M. Reutzel-Edens, C. A. Mitchell, Org. Process Res. Dev., 2000, 4, 396.

[5] A. Nangia, Acc. Chem. Res., 2008, 41, 595.

[6] A. J. Cruz-Cabeza, J. Bernstein, Chem. Rev., 2014, 114, 2170.

[7] T. L. Threlfall, Analyst, 1995, 120, 2435.

[8] J. Haleblian, W. McCrone, J. Pharm. Sci., 1969, 58, 911.

[9] L. Borka, J. K. Haleblian, Acta Pharm. Jugosl., 1990, 40, 71.

[10] M. L. Peterson, M. B. Hickey, M. J. Zaworotko, Ö. Almarsson, J. Pharm. Pharmaceut. Sci., 2006, 9, 317.

[11] B. S. Ghotra, S. D. Dyal, S. S. Narine, Food Res. Int., 2002, $35,1015$.

[12] B. J. D. Le Révérend, P. J. Fryer, S. Coles, S. Bakalis, J. Am. Oil Chem. Soc., 2010, 87, 239.

[13] Z. Hao, A. Iqbal, Chem. Soc. Rev., 1997, 26, 203.

[14] H. Zollinger, Color Chemistry, 3rd ed. Wiley-VCH, Weinheim, 2001.

[15] N. Harada, S. Karasawa, T. Matsumoto, N. Koga, Cryst. Growth Des., 2013, 13, 4705.

[16] Z. He, L. Zhang, J. Mei, T. Zhang, J. W. Y. Lam, Z. Shuai, Y. Q. Dong, B. Z. Tang, Chem. Mater., 2015, 27, 6601.

[17] T. Khan, Y. Tang, Z. Sun, S. Zhang, M. A. Asghar, T. Chen, S. Zhao, J. Luo, Cryst. Growth Des., 2015, 15, 5263.

[18] S. J. Yoon, J. W. Chung, J. Gierschner, K. S. Kim, M. G. Choi, D. Kim, S. Y. Park, J. Am. Chem. Soc., 2010, 132, 13675.

[19] O. S. Wenger, Chem. Rev., 2013, 113, 3686

[20] E. L. Harty, A. R. Ha, M. R. Warren, A. L. Thompson, D. R. Allan, A. L. Goodwin, N. P. Funnell, Chem. Commun., 2015, $51,10608$.

[21] C. Reus, T. Baumgartner, Dalton Trans., 2016, 45, 1850.

[22] V. López-Mejías, J. W. Kampf, A. J. Matzger, J. Am. Chem. Soc., 2012, 134, 9872.

[23] S. K. Chandran, N. K. Nath, S. Roy, A. Nangia, Cryst. Growth Des., 2008, 8, 140.

[24] N. K. Nath, A. Nangia, Cryst. Growth Des., 2012, 12, 5411.

[25] S. Roy, A. Naniga, Cryst. Growth Des., 2007, 7, 2047.

[26] R. Thakuria, N. K. Nath, S. Roy, A. Nangia, CrystEngComm, 2014, 16, 4681 .

[27] G. R. Desiraju, R. Parthasarathy, J. Am. Chem. Soc., 1989, $111,8725$.

[28] S. L. Price, A. J. Stone, J. Lucas, R. S. Rowland, A. E. Thornley, J. Am. Chem. Soc., 1994, 116, 4910.

[29] J. P. M. Lommerse, A. J. Stone, R. Taylor, F. H. Allen, J. Am. Chem. Soc., 1996, 118, 3108.

[30] C. M. Reddy, M. T. Kirchner, R. C. Gundakaram, K. A. Padmanabhan, G. R. Desiraju, Chem. Eur. J., 2006, 12, 2222.

[31] B. K. Saha, A. Nangia, Heteroatom Chem., 2007, 18, 185.

[32] C. B. Aakeröy, N. C. Schultheiss, A. Rajbanshi, J. Desper, Cryst. Growth Des., 2009, 9, 432.

[33] T. Gelbrich, T. L. Threlfall, M. B. Hursthouse, CrystEngComm, 2012, 14, 5454.

[34] G. Kaur, P. Panini, D. Chopra, A. R. Choudhury, Cryst. Growth Des., 2012, 12, 5096.

[35] H. R. Khavasi, A. A. Tehrani, CrystEng Comm, 2013, 15, 5813.

[36] K. Shirai, A. Yanagisawa, H. Takahashi, K. Fukunishi, M. Matsuoka, Dyes Pigm., 1998, 39, 49.

[37] J. H. Kim, S. R. Shin, M. Matsuoka, K. Fukunishi. Dyes Pigm., 1998, 39, 341.

[38] K. Shirai, M. Matsuoka, K. Fukunishi. Dyes Pigm., 1999, 42, 95.

Title

Role of halogen substituents in a series of polymorphic 2,5-diamino-3,6-dicyanopyrazine derivatives with highly flexible groups
File Name revised_ortho_Z 07.09.2018 Krist_1
Page 17 (18) 
[39] S. Matsumoto, Y. Uchida, M. Yanagita, Chem. Lett., 2006, $35,654$.

[40] Y. Akune, H. Gontani, R. Hirosawa, A. Koseki, S. Matsumoto, CrystEngComm, 2015, 17, 5789.

[41] RAPID-AUTO: Rigaku Corporation, 1998, Tokyo, Japan.

[42] CrystalClear: Rigaku Corporation, 1999, Tokyo, Japan.

[43] SHELX-97: G. M. Sheldrich, Acta Cryst., 2008, A64, 112.

[44] CRYSTALS Issue 11: J.R. Carruthers, J.S. Rollett, P.W. Betteridge, D. Kinna, L. Pearce, A. Larsen, E. Gabe. Chemical Crystallography Laboratory, 1999, Oxford, UK.

[45] CrystalStructure 4.0: Crystal Structure Analysis Package, Rigaku Corporation, 2000-2010, Tokyo, Japan.

[46] Mercury: C. F. Macrae, P. R. Edgington, P. McCabe, E. Pidcock, G. P. Shields, R. Taylor, M. Towler, J. van de Streek, J. Appl. Cryst., 2006, 39, 453.

[47] Gaussian 09, Revision B.01. M. J. Frisch, G. W. Trucks, H. B. Schlegel, G. E. Scuseria, M. A. Robb, J. R. Cheeseman, G. Scalmani, V. Barone, B. Mennucci, G. A. Petersson, H. Nakatsuji, M. Caricato, X. Li, H. P. Hratchian, A. F. Izmaylov, J. Bloino, G. Zheng, J. L. Sonnenberg, M. Hada, M. Ehara, K. Toyota, R. Fukuda, J. Hasegawa, M. Ishida, T. Nakajima, Y. Honda, O. Kitao, H. Nakai, T. Vreven, J. A. Montgomery, Jr., J. E. Peralta, F. Ogliaro, M. Bearpark, J. J. Heyd, E. Brothers, K. N. Kudin, V. N. Staroverov, T. Keith, R. Kobayashi, J. Normand, K. Raghavachari, A. Rendell, J. C. Burant, S. S. Iyengar, J. Tomasi, M. Cossi, N. Rega, J. M. Millam, M. Klene, J. E. Knox, J. B. Cross, V. Bakken, C. Adamo, J. Jaramillo, R. Gomperts, R. E. Stratmann, O. Yazyev, A. J. Austin, R. Cammi, C. Pomelli, J. W. Ochterski, R. L. Martin, K. Morokuma, V. G. Zakrzewski, G. A. Voth, P. Salvador, J. J. Dannenberg, S. Dapprich, A. D. Daniels, O. Farkas, J. B. Foresman, J. V. Ortiz, J. Cioslowski, D. J. Fox. Gaussian, Inc., Wallingford CT, 2010.

[48] J. D. Chai, M. Head-Gordon, Phys. Chem. Chem. Phys., 2008, 10, 6615 .

[49] P. J. Hay, W. R. Wadt. J. Chem. Phys., 1985, 82, 270.

[50] M. F. Sanner, J.-C. Spehner, A. J. Olson. Biopolymers, 1996, 38,305 .

[51] A. Gavezzotti, New J. Chem., 2011, 35, 1360.

[52] J. J. McKinnon, M. A. Spackman, A. S. Mitchell, Acta Cryst., 2004, B60, 627.

[53] ConQuest: I. J. Bruno, J. C. Cole, P. R. Edgington, M. Kessler, C. F. Macrae, P. McCabe, J. Pearson, R. Taylor, Acta Crystallogr., Sect. B: Struct. Sci., Cryst. Eng. Mater., 2002, 58, 389.

[54] L. Yu, J. Pharm. Sci., 1995, 84, 966.

[55] A. Mukherjee, S. Tothadi, G. R. Desiraju, Acc. Chem. Res., 2014, 47,2514

[56] H. P. G. Thompson, G. M. Day, Chem. Sci., 2014, 5, 3173.

Title

Role of halogen substituents in a series of polymorphic 2,5-diamino-3,6-dicyanopyrazine derivatives with highly flexible groups 